\title{
EVALUATION OF THE EFFICACY OF FIBER GLASS SPLINTING FOR FIXATION OF DENTO-ALVEOLAR FRACTURES IN CHILDREN
}

\author{
Hager K. Khidrr, Samraa A. El Sheikh², Lydia N. Melek ${ }^{3}$
}

\begin{abstract} are several points of differentiation between the two; the most important one is growth.

OBJECTIVES: To evaluate the efficacy of a new fiber glass splint for fixation of dentoalveolar fractures in children. fourth months' post operatively using cone beam software. esthetic, and non-invasive technique.

KEY WORDS: Fiber glass splint,dentoalveolar fracture, bone density, children.

- B.D. S Faculty of dentistry Alexandria University, Alexandria, Egypt.

2- Professor of Oral and Maxillofacial Surgery, Faculty of Dentistry, Alexandria University, Alexandria, Egypt.

3- Lecturer of Oral and Maxillofacial SurgeryFaculty of Dentistry, Alexandria University, Alexandria, Egypt.
\end{abstract}

INTRODUCTION: Dentoalveolar fractures of children are a common manifestation of trauma, but it is different from trauma in adults. There

MATERIALS AND METHODS: This was a prospective clinical trial. Ten children with dentoalveolar fractures were selected from the outpatient clinic of The Oral and Maxillofacial Surgery, Faculty of dentistry, Alexandria University. The patients were treated with closed reduction and fixation with new splint (F-Splint Aid). Clinical and radiographic evaluation were done up to 4 months post operatively for postoperative swelling, Inflammation or infection and stability of fracture segment. The bone density was measured and compared at the first and

RESULTS: There was a decrease of pain from time of treatment to the seventh day after treatment which was statistically significant, the subsidence of edema and decrease of mobility were also statistically significant, and there was an increase in the mean radiographic bone density from 1 month to 4 months post operatively which were found to be statistically significant $(\mathrm{T}$ value $=5.639, \mathrm{P}$ value $<0.001)$.

CONCLUSIONS: It was concluded that the use of F. Splint. Aid in the treatment of dentoalveolar fracture of children is cheap, hygienic,

\section{INTRODUCTION}

Dental trauma is an important public health problem, due to high prevalence, especially among children and teenagers (1). Additionally, it negatively impacts on the person's quality of life (2), because of the esthetic, psychological, social, functional, and therapeutic problems (3).

The reported incidence of pediatric maxillofacial injuries accounts for $4-6 \%$ of the total injuries. The prevalence of pediatric facial fractures is lowest in infants and increases progressively with increasing age. Among all cases of pediatric maxillofacial trauma, the majority accounts for dentoalveolar trauma and soft tissue injuries, whereas the frequency of facial bone fractures is considerably low (4).

The goal of treatment of these pediatric fractures is to restore the underlying bony architecture to the pre-injury position, in a stable fashion, as non-invasively as possible without hampering the permanent tooth germs, with minimal residual esthetic and functional impairment (5). The principles of management of fractures differ in children when compared to adults, in children open reduction and osteosynthesis of the fracture have a negative effect on the skeletal growth and unerupted teeth, as it involves two-stage surgeries because of the need for plate removal after healing (4-6), so simple splinting method after closed reduction is the safest method unless the fracture fragments are severely displaced. Also children have great osteogenic potential and faster healing rate than adult, so anatomical reduction must be accomplished earlier, and immobilization time must be shorter (7-9).

Splint is defined as a device used to support, protect or immobilize teeth that have been loosened, replanted, fractured or subjected to endodontic procedures, until late 1970, rigid splints were used for immobilization of jaw bones, which didn't allow physiological tooth movement and were also associated with great frequency of pulp necrosis and canal obliteration. Semi rigid splinting is therefore a common and preferred method that allows controlled passive mobilization of the traumatized tooth (10).

The disadvantages of the known extra coronal splint, is that it is not esthetically pleasing due to excessive bulk of resins or composites, wires showing through the resin or composite material and the staining of these materials, also when composites or resins are used alone, there is often fracturing or shearing of the material interproximally (11).

The development of fiber-reinforced composite (FRC) technology has brought a new material into the realm of metal-free, adhesive esthetic dentistry (12). Not only the combination of composite resin and FRC has been shown to have significant benefits in terms of mechanical properties (13), the possibility of direct chair side application and the ability to bond to tooth structure make FRC an attractive choice for a variety of dental applications (14).

Different fiber types such as glass fibers, carbon fibers, Kevlar fibers, Vectran fibers and polyethylene fibers have been added to composite materials to increase its strength (15).

Fiber-glass splint has been successfully introduced into the market since 1989 with a monolayer fiberglass strip. FSplint-Aid is a new product consists of 6 layers' fiberglass band soaked in bonding agent, the layers already sewn together one over the other. Thus, the individual layers no longer have to be applied onto each other, saving significantly valuable chair time, at the same time the new multilayered version maintains its traditional flexibility, offering an absolutely reliable method for splinting and general reinforcements of temporary bridges (16). 
The Fiber glass splint technique, achieves excellent, noninvasive results in just one session, applying the fiberglass is quick and easy, saving the dentist and patient time and money (16).

The aim this study was to evaluate the efficacy of (FSplint-Aid) for fixation of dentoalveolar fractures in children.

\section{MATERIALS AND METHODS}

Study design: This is a prospective clinical trial; ten children with history of trauma were selected from the outpatient clinic of The Oral and Maxillofacial Surgery, Faculty of dentistry, Alexandria University on the following basis:

\section{Inclusion criteria}

Cases with recent dentoalveolar fracture of upper or lower jaw, free from any relevant systemic disease, patient age ranging from 6 to 12 years old and with sufficient number of sound teeth around the fracture line for retention of the splint.

\section{Exclusion criteria}

Unco-operative patients and patients with uncontrolled systemic disease or Comminuted fracture.

All the participating patients' parents gave informed consent for participation in the study.

The study was performed after gaining the approval of the Research Ethics Committee, Faculty of Dentistry, Alexandria University.

\section{Materials}

Armamentarium: the product has two types:

(F-Splint-Aid) Fiberglass strip 6 Layers $12 \mathrm{~cm} / 4 \mathrm{~mm}$, soaked in bonding agent, ready for use, +5 Clip\&Splint, enough for 4-7 applications.

(F-Splint-Aid Slim) Fiberglass strip 3 Layers $12 \mathrm{~cm} / 2$ $\mathrm{mm}$ soaked in bonding agent ready for use, +5 Clip \& Splint, enough for 4-7 applications.

\section{Methods}

\section{A-pre-operative phase:}

For every patient preoperative evaluation was carried out through proper history taking and clinical and radiological examination as follows;

\section{1-History of the patient}

Detailed pre-operative data was collected from all patients including full personal data (name, age, gender, address) followed by chief complaint, history of present illness, past and present medical and dental history, etiology of the fracture, time of trauma (not more than 24 hours from the trauma), place, type of injury and immediate measures were essential information.

\section{2-Clinical examination}

All patients were subjected to full clinical examination by inspection and palpation of the fracture site both extra orally and intra orally.

\section{A- Extra oral examination}

Inspection: Washing face with warm water to show any ecchymosis, swelling, soft tissue laceration, deformity of bony contour of the jaw or blood stained saliva dribbling from the corner of the mouth.

Deviation during opening and closing, abnormal movement of the jaw, presence of open bite, swelling and ecchymosis indicate the site of expected jaw fractures.

Palpation: Of middle third of face, the condylar region and along the lower border of the mandible for step deformity, tenderness, crepitus and anesthesia of lower lip.

\section{B- Intra oral Clinical examination}

Inspection: of lips and gum, for laceration, edema, ecchymosis and fracture hematoma in the buccal and lingual sulci, teeth may be avulsed, mobile, subluxated or fractured, deformed alveolus causing defect of occlusion.

Palpation: of lip and cheeks if injured for the presence of a tooth or part of a tooth or any foreign body in the soft tissues, and palpation of alveolus for bony deformity, crepitus, tenderness or comminution. Each tooth was examined for mobility across the site of fracture, and vitality test was done by pulp tester.

\section{C: Radiographic examination}

Panoramic radiographs were taken to show the fracture line and any pathological lesion, state of eruption of permanent tooth, and any fractured tooth.

\section{D: Photographic documentation:}

The use of preoperative and postoperative photography was very useful for documentation purposes. (Figure 1)

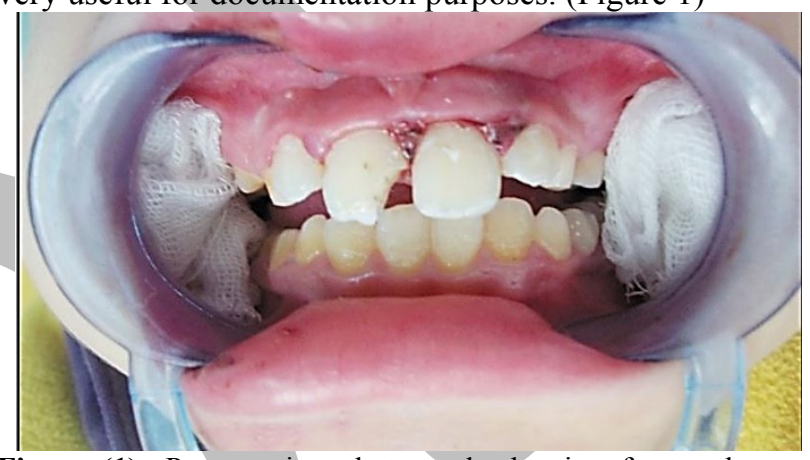

Figure (1): Preoperative photograph showing fractured upper right central and luxated right and left upper central

\section{B: Operative phase}

All patients were operated during the first or second day of trauma.

For all patients the following steps were performed:

1- Cleaning of mouth from debris and tooth fragments, and control of bleeding with cotton-wool and washing with warm saline to remove caked or coagulated blood.

2-Local infiltration or nerve block anesthesia using Mepivacaine hydrochloride $\quad 3 \% \quad$ (Alexandria pharmaceuticals and chemicals industries (AXPH), Alexandria, Egypt) with $0,05 \mathrm{mg}$ levonordefrin injection as a vasoconstrictor agent.

3-The fractured teeth, tooth fragments and teeth in fracture line with impaired blood supply were extracted before suturing of the soft tissue laceration to avoid infection.

4-Repositioning of the mobile, subluxated and freshly avulsed teeth, Bone fragment reduced and aligned in occlusion by bi-digital pressure until its normal position has been reestablished indicated by alignment of the dental arch in proper occlusion. Strong force for reduction was usually required.

5-Choosing the suitable neighboring teeth for the treatment (at least one intact tooth on each side of the fractured tooth) to act as an abutment.

6-The lingual or buccal surface was cleaned with a light polishing paste without fluoride, in order to remove the existing plaque biofilm that could hinder the adherence of the fiber-glass strip.

7-Involved teeth and neighboring healthy teeth were gently dried with compressed air or absolute alcohol and kept dry during the fixation procedure. Care was taken that compressed air and absolute alcohol are not allowed to enter 
the soft-tissue wound. Points of splint fixation were etched with phosphoric acid for 20 seconds (figure 2).

8 -The etch gel was removed by saline irrigation. Make sure to direct the saline jet in a direction away from soft-tissue wounds and to place a suction tube to remove the spray of the saline and etch gel. The fixation spots were then dried, isolate the field by cotton rolls and suction tubes.

9-The required length of the fiber-glass band was measured with floss and cut. Then was put on a glass plate and impregnated with Polydentia's "Fiber-Bond".

10-Once positioned on the teeth; the fiber-glass band was firmly kept in interdental spaces using the clips, and then light cured for 30 seconds (figure 3 ).

11-Once the polymerization was completed; the fiber-glass band was coated with a thin layer of flowable composite in order to grant a general protection.

12-Using thin and narrow abrasive strips or suitable hand piece, the interdental spaces were finished (figure 4).

13-Occlusion was checked; no premature occlusal contacts were allowed.



Figure (2): Acid etching

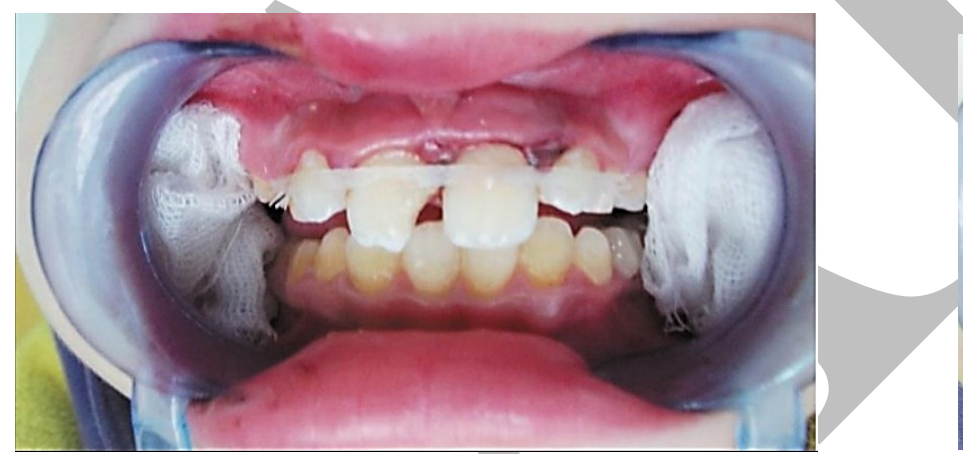

Figure (3): Fiber glass splinting

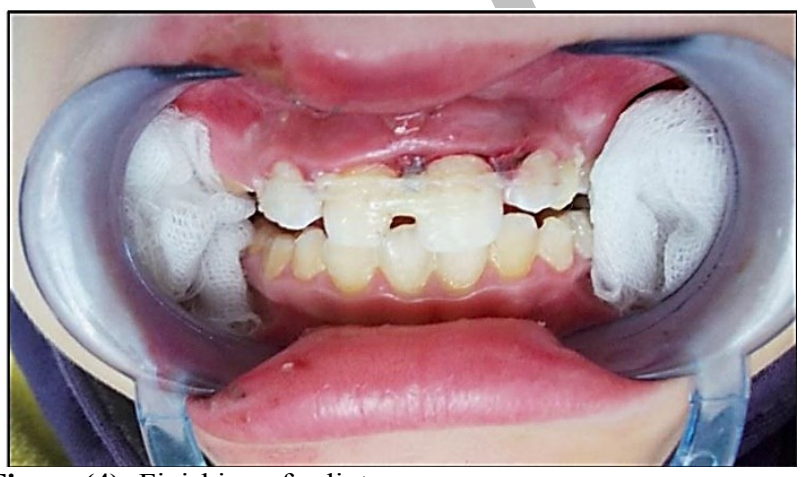

Figure (4): Finishing of splint

\section{C-Post operative phase:}

All patients were instructed to feed on a soft high protein and caloric diet with adequate amounts of fluids, avoid chewing on operated side during the splinting period, and to make cold fomentations for several hours after treatment to prevent edema.

The parents were informed about the importance of maintaining meticulous oral hygiene and tooth brushing after each meal, and regularly returning for clinical and radiographic follow up.

\section{Medications:}

1- All patients received: antibiotics: Amoxicillin (Emox, Epico Pharmaceutical Co. Egypt) $250 \mathrm{mg} / 5 \mathrm{ml}$ suspension every 8hours, for seven days' post operatively.

2-Anti-inflammatory: Ibuprofen (Megafen.N. Rameda Pharmaceuticals. Egypt). $100 \mathrm{mg} / 5 \mathrm{ml}$ syrup, 1 teaspoon every 8hours, for seven days' post operatively.

3-Chlorhexidine (Hexitol by Arab Drug Co. Cairo, Egypt) mouth wash for 5days, started from the day following the surgery.

\section{Follow up phase}

\section{1- Clinical follow up}

During the splinting period all patients were recalled after 24 hours, on days three and seven post operatively and then at weekly intervals for 6 weeks.

If sutures have been used, they were removed on the sevenths to tenth postoperative day to allow complete healing.

After three to four weeks the proper bone healing was assured by detection of the stability of occlusion and the stability of reduced fractured bony segments, then the strip inter proximally was cut with a diamond bur, then the strip was removed from the abutment by a scalpel blade between the strip and the teeth on the most distal end. The remaining composite was removed with a tungsten carbide bur in a low speed hand piece under coolant water and surfaces were polished with disks (figure 5)

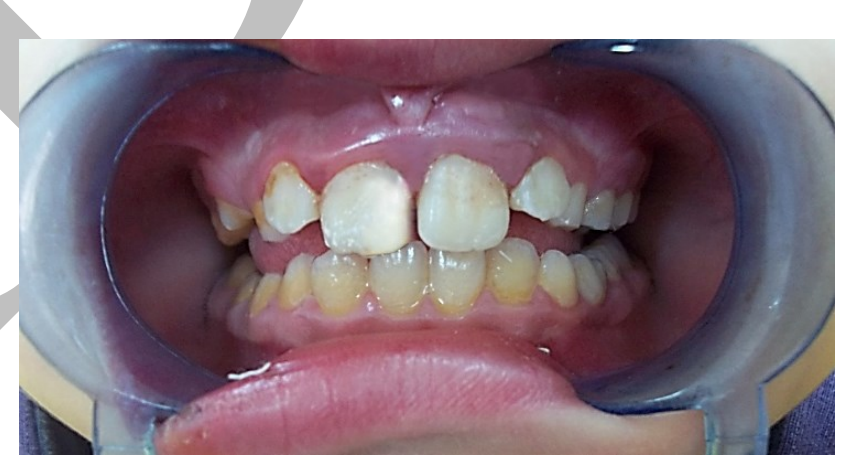

Figure (5): 4 weeks after treatment

\section{Clinical evaluation}

1-Pain intensity was assessed using visual analogue scale (VAS): (O: no pain, 10: unbearable distress) before treatment and on day1, 3, 7 after splinting (17).

2-Post-operative swelling ( 0 - absence, 1 - mild, 2- moderate, 3- severe) (18).

3-Signs of inflammation or infection.

4-Occlusion checked by intercuspation and functional occlusion in all excursion and premature contacts located by articulating papers and wax sheet.

5-Mobility of teeth was measured by pushing the teeth gently and alternatively in a facio-lingual direction using the blunt ends of two mirror handles, (grade I-slightly more than normal $<1 \mathrm{~mm}$ horizontal movement, grade IImoderately more than normal 1-2mm horizontal movement, grade III-severe mobility $>2 \mathrm{~mm}$ horizontal or any vertical movement (19). 
6-Stability of the fracture segments.

7- The patient ability to maintain oral hygiene, and periodontal health evaluated for presence of gingival inflammation, pocketing or bleeding.

8-Looseness of the splint.

9-Pulp testing electrically and thermally.

\section{2- Radiographic follow up}

Segmental cone beam radiographs were performed for all patients after one month and then after four months post operatively to assure proper healing of the bone, disappearance of fracture line, presence of root or bone resorption or ankylosis, root development and evaluation of bone density.

\section{3- Evaluation of bone density}

The bone density (20) was measured and compared at the first and fourth months' post operatively using cone beam software (On Demand 3DAPP-DBM).

Every radiograph was studied through the following steps: Region of interest (ROI) was chosen around the root of splinted tooth or teeth in the axial view. ROI surface area was adjusted to be $(55 \times 90)$ around the tooth. Then the average density and standard deviation were collected. This was done for the two CBCT view of every patient and was represented in a schedule (Figure 6a, b). Differences between the values calculated from the $4^{\text {th }}$ month postoperative $\mathrm{CBCT}$ view and $1^{\text {st }}$ month postoperative CBCT view were calculated representing the progress of bone density after 3 months, and listed in a schedule.
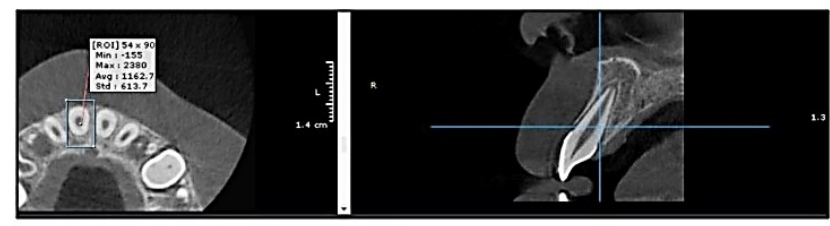

(a)



(b)

Figure (6a, b): (a): Cone beam film after 1 month, (b): cone beam film after 4 months showing measuring of bone density

Statistical analysis of the data (21):

Data were fed to the computer and analyzed using IBM SPSS software package version 20.0. Quantitative data were described using range (minimum and maximum), mean, standard deviation and median. Significance of the obtained results was judged at the $5 \%$ level.

\section{The used tests were}

\section{1- Paired t-test}

For normally quantitative variables, to compare between two periods

\section{2 -Wilcoxon signed ranks test}

For abnormally quantitative variables, to compare between two periods.

\section{RESULTS}

\section{1-Clinical evaluation}

\section{A: Pre-operative clinical data}

This study was carried on ten children of both genders, had been recently subjected to trauma which cause dentoalveolar fracture that require treatment by closed reduction and fixation.

The age distribution of patients in this study ranged between 6 to 12 years with a mean value $(9 \pm 1.82)$.

The gender distribution was seven males and three females with a 3:1 male to female ratio.

The etiology of fracture in this study showed that fall was the main etiological factor ( 6 cases), followed by sport ( 2 cases), road traffic accidents (1 case) and interpersonal violence ( 1 case).

Concerning the site of fracture, the upper incisor region was the most affected region representing $80 \%$ of all cases followed by the lower incisor region $20 \%$.

Six patients showed mild (grade 1) swelling, and four patients showed moderate (grade 2) swelling according to the site of fracture.

All patients had pain sensation assessed using Visual analogue scale (VAS) ranging from 2 to 6 degree, with a median value 4 degree.

Eight patients showed derangement of occlusion due to lateral luxation (3cases), extrusion ( 2 cases), intrusion of teeth ( 2 cases) and alveolar fracture ( 1 case) the rest of cases had normal occlusion.

All patients showed tooth mobility ranging from grade one to three.

\section{B: Operative clinical data}

All patients were operated during the first or second day of trauma under local anesthesia.

All patients were treated by closed reduction and fixation using (F-Splint- Aid) for three to four weeks.

\section{$\mathrm{C}$ : Post-operative clinical data}

Post-operative pain

The data collected from the measurement of the mean pain visual analogue scale (VAS) score values were tabulated before treatment and on day1, 3, and 7 after splinting.

The mean pain VAS score of all patients before treatment was $3.60 \pm 1.17$, while it was $2.70 \pm 1.06,2.02 \pm$ 00.92 and $1.0 \pm 0.67$ at day 1,3 and 7 respectively. This means that the decrease of pain from time of treatment to the seventh day was statistically significant (Table 1).

\section{Post-operative swelling}

Five patients showed subsidence of edema after three days' post operatively, and five patients showed subsidence of edema after seven days postoperatively.

The subsidence of edema was not statistically significant from before treatment to day 1 post operatively, but it was statistically significant at the $3 \mathrm{rd} \& 7$ th days postoperatively (Table 2).

\section{Mobility}

After splinting there was not any mobility due to fixation, the mean value was $0.0 \pm 0.0$, after splint removal it was ranging from zero to one with a mean value $(0.20 \pm 0.42)$, the decrease of mobility was statistically significant after treatment.

\section{Occlusion}

Occlusion was checked in all cases which had been reduced to maintain proper occlusion, no cases of malocclusion were found after reduction and fixation so there was no need for selective grinding. 


\section{Stability of fracture segment}

The site of fracture revealed properly aligned segments with no step deformities where no movement of the fracture segments was noticed in any patient.

Table (1): Showing comparison between the studied periods according to pain $(\mathrm{n}=10)$

\begin{tabular}{|r|c|c|c|c|}
\hline & \multicolumn{4}{|c|}{ Pain } \\
\cline { 3 - 5 } & \multirow{2}{*}{$\begin{array}{c}\text { Before } \\
\text { treatment }\end{array}$} & \multicolumn{3}{|c|}{ After } \\
\cline { 3 - 5 } & Day1 & Day3 & Day 7 \\
\hline $\begin{array}{r}\text { Min. }- \\
\text { Max. }\end{array}$ & $2.0-6.0$ & $2.0-5.0$ & $1.0-4.0$ & $\begin{array}{c}0.0- \\
2.0\end{array}$ \\
$\begin{array}{r}\text { Mean } \\
\pm \text { SD. }\end{array}$ & $3.60 \pm 1.17$ & $\begin{array}{c}2.70 \pm \\
1.06\end{array}$ & $\begin{array}{c}2.020 \pm \\
0.92\end{array}$ & $\begin{array}{c}1.0 \pm \\
0.67\end{array}$ \\
Median & 3.0 & 2.0 & 2.0 & 1.0 \\
\hline P Before & & $0.003^{*}$ & $0.006^{*}$ & $0.004^{*}$ \\
\cline { 3 - 5 } $\begin{array}{r}\text { Sig. bet. } \\
\text { periods }\end{array}$ & & $\mathrm{p}_{1}=0.025^{*}, \mathrm{p}_{2}=0.004^{*}, \mathrm{p}_{3}=0.003^{*}$ \\
\hline
\end{tabular}

$\mathrm{P}_{\text {Before: }} \mathrm{p}$ value for Wilcoxon signed ranks test for comparing between before and each other periods

$\mathrm{p}_{1}$ : $\mathrm{p}$ value for Wilcoxon signed ranks test for comparing between day 1 and day 3

$\mathrm{p}_{2}$ : $\mathrm{p}$ value for Wilcoxon signed ranks test for comparing between day 1 and day 7

$\mathrm{p}_{3}$ : $\mathrm{p}$ value for Wilcoxon signed ranks test for comparing between day 3 and day 7

*: Statistically significant at $\mathrm{p} \leq 0.05$

Table (2): Showing comparison between the studied periods according to swelling $(\mathrm{n}=10)$

\begin{tabular}{|c|c|c|c|c|}
\hline & \multicolumn{4}{|c|}{ Swelling } \\
\hline & \multirow{2}{*}{$\begin{array}{c}\text { Before } \\
\text { treatment }\end{array}$} & \multicolumn{3}{|c|}{ After } \\
\hline & & Day1 & Day3 & Day 7 \\
\hline $\begin{array}{r}\text { Min. - } \\
\text { Max. }\end{array}$ & $1.0-2.0$ & $1.0-2.0$ & $0.0-1.0$ & $\begin{array}{c}0.0- \\
0.0\end{array}$ \\
\hline $\begin{array}{r}\text { Mean } \pm \\
\text { SD. }\end{array}$ & $1.40 \pm 0.52$ & $\begin{array}{c}1.40 \pm \\
0.52\end{array}$ & $\begin{array}{c}0.50 \pm \\
0.53\end{array}$ & $\begin{array}{c}0.0 \pm \\
0.0\end{array}$ \\
\hline Median & 1.0 & 1.0 & 0.50 & 0.0 \\
\hline$P_{\text {Before }}$ & & 1.000 & $0.003^{*}$ & $0.004^{*}$ \\
\hline $\begin{array}{r}\text { Sig. bet. } \\
\text { periods }\end{array}$ & & \multicolumn{3}{|c|}{$\mathrm{p}_{1}=0.003^{*}, \mathrm{p}_{2}=0.004^{*}, \mathrm{p}_{3}=0.025^{*}$} \\
\hline
\end{tabular}

$\mathrm{P}$ Before: $\mathrm{p}$ value for Wilcoxon signed ranks test for comparing between before and each other periods

$\mathrm{p}_{1}$ : $\mathrm{p}$ value for Wilcoxon signed ranks test for comparing between day 1 and day 3

$\mathrm{p}_{2}$ : $\mathrm{p}$ value for Wilcoxon signed ranks test for comparing between day 1 and day 7

$\mathrm{p}_{3}$ : $\mathrm{p}$ value for Wilcoxon signed ranks test for comparing between day 3 and day 7

*: Statistically significant at $\mathrm{p} \leq 0.05$

\section{Signs of inflammation or infection}

No signs of inflammation or infection were found in any of the cases of this study.

\section{Looseness of the splint}

Looseness of the splint was found in $40 \%$ of cases, and was splinted again.

\section{Oral hygiene and periodontal health}

There was no gingival inflammation, pocketing or bleeding, the splints were hygienic and did not cause allergy.

\section{Pulp vitality}

All teeth maintained their pulp vitality, except for one case which was referred to the endodontic dentist for further follow up and root canal treatment if needed.

\section{2: Radiographic evaluation:}

In all patients there was proper healing of bone and disappearance of fracture line, no signs of root or bone resorption or ankylosis, and roots development were not interrupted.

\section{Bone density}

After one month the mean radiographic bone density of all patients were $1089.01 \pm 123.86$ Hounsfield Unit.

After four months the mean radiographic bone density of all patients was $1239.79 \pm 181.93 \mathrm{H} \mathrm{U}$. This increase in the mean radiographic bone density from 1 month to 4 months post operatively was found to be statistically significant ( $T$ value $=5.639$,

$\mathrm{P}$ value $<0.001)$ (Table 3 ).

Table (3): Showing comparison between After 1 month and After 4 months according to bone density

\begin{tabular}{|l|c|c|c|c|}
\hline & \multicolumn{2}{|c|}{ Bone density } & \multirow{2}{*}{ t } & \multirow{2}{*}{ p } \\
& $\begin{array}{c}\text { After 1 } \\
\text { month }\end{array}$ & $\begin{array}{c}\text { After 4 } \\
\text { months }\end{array}$ & t & \\
\hline Min. - & $939.80-$ & $1015.0-$ & & \\
Max. & 1304.10 & 1780.70 & & \\
Mean \pm & $1089.01 \pm$ & $1239.79 \pm$ & $5.639^{*}$ & $<0.001^{*}$ \\
SD. & 123.86 & 181.93 & & \\
Median & 1067.90 & 1230.65 & & \\
\hline
\end{tabular}

t: Paired t-test

$*$ : Statistically significant at $\mathrm{p} \leq 0.05$.

\section{DISCUSSION}

This current study was carried out on ten children of both genders; all of the patients had been subjected to trauma to periodontal supporting tissues or alveolar bone requiring treatment by closed reduction and fixation.

The incidence of fracture in males compared to females was $3: 1$; this is probably due to the higher level of physical activity among boys. This was in accordance with Hall (22), and was higher than Turkistani and Hanno (23), who said that boys are twice as likely as girls to report dentoalveolar trauma and are much more likely to experience such trauma more than once.

Concerning the site of fracture, the upper incisor region was the most affected region representing $80 \%$ of all cases because it is prone to injuries, followed by the lower incisor region, this was in accordance with Andreasen and Andreasen (24) who reported that the majority of traumatic injuries occur in the maxillary central incisors, and with Dewhurst et al (25) who reported that a common location of the alveolar process fracture is the anterior region.

Concerning the etiology of dentoalveolar fracture in this study, falls were the main etiological factor representing $60 \%$ of all cases, followed by sports, road traffic accidents and interpersonal violence. This is found to be in agreement with Carroll et al (26) who mentioned falls to be the common cause of facial fractures in children.

Closed reduction is the method of choice in pediatric patients. The main advantage of closed reduction in this age group is that it prevents injury to the developing dentition, avoids growth disturbances, and provides a good reduced position; another advantage of closed reduction is that it can be performed on outpatient basis under local anesthesia so more patient compliance and cooperation is attained with 
fewer complications (27). In addition, the use of closed reduction technique is of great impact due to the generally poor socioeconomic status of patients. Schmidt et al (28) stated that the costs of open reduction and internal fixation are nearly three folds higher than conventional closed reduction. Finally, fiber glass splints have fair prices for poor patients.

The stabilization of injured teeth through using the adjacent sound teeth is considered the best practice to support the tooth at right position and in function because it allows the exposure of the injured teeth to physiologic forces existing in oral environment (29). Experimentally, Fixation of the traumatized tooth was performed on two neighboring teeth, as extending a splint to more than one adjacent firm tooth has no beneficial effect (30).

In this study all the patients were treated by proper manual closed reduction of bone and repositioning of mobile, luxated and freshly avulsed teeth, followed by fixation with fiber glass splint.

All cases were treated within two days' post traumatic, as the time interval elapsed since injury is very important because it influences the choice of treatment (24), so immediate repositioning and stabilization of the teeth in their anatomically correct positions are essential to optimize healing of the periodontal ligament and neurovascular supply, while maintaining esthetic and functional integrity (31). According to Andreasen and Andreasen (24) repositioning of the dislocated teeth is more difficult after 48 hours of the injury.

Fiber glass splint is a flexible splint that allow slight mobility to aid the functional reorientation of the periodontal membrane fibers, because previous studies reported that rigid splinting, i.e. immobilization, or a prolonged splinting period may lead to extensive periodontal ligament healing complications, such as dentoalveolar ankylosis or external root resorption (replacement resorption) (32).

Regarding the surgical technique of F splint aid, it was proved to be easy and not time consuming, since the entire time required did not exceed 20 minutes, as no laboratory work is needed. Many of the splinting techniques were time-consuming, not only were the splints difficult to fabricate but also difficult to remove (33).

Severe dental injuries, unlike these chronic conditions, cause immediate unexpected pain and disfigurement, trauma produces acute and chronic pain that can lead to time off school, lost sleep and commuting for treatment (34). The stabilization reduces or avoids pain, offers comfort to patient and protects the teeth from traumatic forces during healing process (29).

This study quantified the perception of pain produced by dental injuries and their treatment by visual analogue scale (VAS), the results showed that the decrease of pain from time of treatment to the seventh day was statistically significant. And all participants agreed that the injury was the most painful event, followed by emergency treatment and splint removal.

Mobility test was made before treatment and after splinting and after splint removal to study the effect of this splint on the periodontal tissue, by palpating the teeth between finger and mirror handle, and showed that the decrease of mobility was statistically significant after treatment.
Another study by Andreasen (35) reported that human teeth splinted for one week reach normal levels of mobility within 3 weeks which was a radical finding at that time.

The present study showed that Fiber Glass Splint had a low working time of removal than arch bars and wires, as their removal doesn't require any type of anesthesia which represents an additional advantage because removal of rigid arch bar splints or interdental wiring is often a difficult process involving unwiring and cutting of wires close to the gingival margins with potential damage to soft tissues (36).

All the patients had clinical stability after removal of the splint at 3 to 4 weeks postoperatively. This finding is in general agreement with those of other studies which reported that splint period for periodontal ligament therapy is two to four weeks, but in case of either lack of periodontal support or marginal bone weakening the ideal period should be postponed for until eight weeks (37).

Fiber glass splint was well tolerated by the patients because it is a biocompatible material having no metal which cause allergy, hygienic as there was no difficulty in maintaining oral hygiene measures around it so no periodontal problems resulted. It also meets the patients' esthetic expectations because its color is similar to the natural tooth.

A review of cases in this study shows no single case of infection or inflammatory complications such as persistent/increased swelling beyond the seventh postoperative day, erythema, pain or purulent discharge from the surgical site, and this zero rate of infection could be attributed to minor surgical maneuver, least traumatic technique, minimal soft tissue and bone manipulation, and routine administration of post-operative antibiotics which was administered for the seven days post operatively, as many studies showed that short-duration therapy is as effective as longer durations, and helps to minimize inadvertent sequelae of antibiotics (38).

Clinical examination of all patients after removal of the splint showed stability of fracture segments as well as proper occlusion. No case showed occlusal disharmony, so there was no need for spot grinding to adjust occlusion and rehabilitation, this was in accordance with Arthur and Berardo (39).

Looseness of the splint was found in $40 \%$ of cases because of loss of adhesion, and required further application of a new strip to remake splinting.

Post-operative follows up of the patients showed no complications at any time of treatment. The low complication rate may be attributed to the fact that minimally displaced fractures were selected. More ever, the use of local anesthesia and closed reduction technique ruled out complications related to prolonged surgery duration under general anesthesia using invasive techniques.

Pulp survival after an injury depends on the extent of the injury, Subluxation injuries were considered to represent minimal damage to the pulpal vasculature, and lateral luxation, extrusion luxation and intrusion luxation injuries represents major damage (40). In the present study, all teeth maintained their pulp vitality except for one case which were referred to the endodontic dentist for further follow up and root canal treatment if needed.

Radio graphically, segmental cone beam radiograph was taken after one and four months post operatively, to assure proper healing, the results demonstrated that there was proper healing of bone and disappearance of fracture line. There was no widening of the periodontal ligament or loss 
of the periodontal ligament space, and there was a steady increase in the mean radiographic bone density from 1 month to 4 months post operatively and this increase was found to be statistically significant.

\section{CONCLUSIONS}

From the results of this study we conclude that:

- Fiber glass splint was proved to be cheap, easy and not time consuming in application or removal.

- Fiber glass splint was noninvasive, well tolerated by the patients; aesthetic, hygienic and there was no difficulty in maintaining oral hygiene.

\section{CONFLICT OF INTEREST}

The authors declare that they have no conflicts of interest.

\section{REFERENCES}

1. Atabek D, Alaçam A, Aydintuğ I, Konakoğlu G. A retrospective study of traumatic dental injuries. Dent Traumatol. 2014; 30:154-61.

2. Ramos-Jorge ML, Bosco VL, Peres MA, Nunes AC. The impact of treatment of dental trauma on the quality of life of adolescents - a case-control study in southern Brazil. Dent Traumatol. 2007; 23:114-9.

3. Marcenes W, Alessi ON, Traebert J. Causes and prevalence of traumatic injuries to the permanent incisors of school children aged 12 years in Jaragua do Sul, Brazil. Int Dent J. 2000; 50:87-92.

4. McGraw BL, Cole RR. Pediatric maxillofacial trauma, age related variations in injury. Arch Otolaryngol Head Neck Surg. 1990; 116:41-5.

5. Aizenbud D, Hazan-Molina H, Emodi O, Rachmiel A. The management of mandibular body fractures in young children. Dent Traumatol .2009; 55: 565-70.

6. Haug RH, Foss J. Maxillofacial injuries in the pediatric patient. Oral Surg Oral Med Oral Pathol Radiol Endod .2009; 90: 126-34.

7. Zimmermann, CE, Troulis MJ, Kaban LB. Pediatric facial fractures: Recent advances in prevention, diagnosis and management. Int J Oral Maxillofac Surg. 2006; 35: 2-13.

8. Kaban LB. Diagnosis and treatment of fractures of the facial bones in children. J Oral Maxillofacial Surg .1993; 51: 722-9.

9. Mohan C, Bhat S, Karikal A, Gupta N. Dept of Oral \& Maxillofac Surgery, Reinforced open cap Splint: A novel therapeutic technique in pediatric mandibular fracture. Heal Talk. 2012; 5: 32-3.

10. Rao A, Rao A, Shenoy R. Splinting--when and how? Dent Update.2011; 38: 341-2.

11. Nathanson D, Moin K. Metal-reinforced anterior tooth replacement using acid-etch composite resin technique. J Prosthet Dent .1980; 43: 408-12.

12. Meiers JC, Kazemi RB, Donadio M. The influence of fiber reinforcement of composite on shear bond strengths to enamel. J Prosthet Dent .2003; 89: 388-93.

13. Vallittu PK. Flexural properties of acrylic resin polymers reinforced with unidirectional and woven glass fibers. J Prosthet Dent. 1999; 81: 318-26.
14. Vallittu PK, Sevelius C. Resin-bonded, glass fiberreinforced composite fixed partial dentures: a clinical study. J Prosthet Dent. 2000; 84: 413-8.

15. Vitale MC, Caprioglio C, Martignone A, Marchesi U, Botticelli AR. Combined technique with polyethlene fibers and composite resins in restoration of traumatized anterior teeth. Dent Traumatol. 2004; 20:172-7.

16. Pearson Dental. F-SPLINT-AID Switzerland. Available at:http://www.polydentia.ch/uploads/tx_iplpdprodotti/Fib er_Splint_brochure_EN_10.pdf

17. Marsh-Richard DM, Hatzis ES, Mathias CW, Venditti N, Daugherty DM. Adaptive visual analog scales: a modifiable software program for the creation, administration and scoring of visual analog scales. Behav Res Methods. 2009; 41: 99-106.

18. Ali Alp Saglam. Effects of tube drain with primary closure technique on postoperative trismus and swelling after removal of fully impacted mandibular third molars. Quintessence Int. 2003; 34: 143-7.

19. Tanaka E, Ueki K, Kikuzaki M, Yamada E, Takeuchi M, Dalla-Bona D. Longitudinal measurements of tooth mobility during orthodontic treatment using a periotest. Angle Orthod. 2005; 75: 101-5.

20. Joly J, de Lime A, da Silva R. Clinical and radiographic evaluation of soft and hard tissue changes around implants: A pilot study. J Periodontal. 2003; 74: 1097103.

21. Kotz S, Balakrishnan N, Read CB, Vidakovic B. Encyclopedia of statistical sciences. $2^{\text {nd }}$ ed. Hoboken, N.J.: Wiley-Interscience, 2006.

22. Hall RK. Injuries of the face and jaws in children. Int J Oral Surg. 1972; 1:65-75.

23. Turkistani J, Hanno A. Recent trends in the management of dentoalveolar traumatic injuries to primary and young permanent teeth. Dent Traumatol. 2011; 27:46-54.

24. Andreasen F, Andreasen J. Crown fractures. In: Andreasen J, Andreasen F, Andersson L (eds). Textbook and color atlas of traumatic injuries to the teeth. 4th ed. Oxford: Blackwell Munksgaard, 2007. pp 280-313.

25. Dewhurst SN, Mason C, Roberts GJ. Emergency treatment of oral dental injures: a review. $\mathrm{Br} \mathrm{J}$ Maxillofacial Surg. 1998; 36:165-75.

26. Carroll MJ, Hill CM, Mason DA. Facial fractures in children. Br Dent J. 1987; 163:23-6.

27. Kumar N, Singh AK, Pandey A, Verma V. An indigenous method for closed reduction of pediatric mandibular parasymphysis fracture. Natl J Maxillofac Surg. 2015; 6:206-8.

28. Schmidt B, Kearns G, Gordon N, Kaban LB. A functional analysis of Maxillomandibular fixation versus rigid internal fixation for treatment of mandibular fracture. $\mathrm{J}$ Oral Maxillofacial Surg. 2000; 58:1206-11.

29. Andreasen JO, Andreasen FM, Mejàre I, Cvek M. Healing of 400 intra-alveolar root fractures. 2. Effect of treatment factors such as treatment delay, repositioning, splinting 
type and period and antibiotics. Dent Traumatol. 2004; 20:203-11.

30. Ebeleseder KA, Glockner K, Pertl C, Stadtler R. Splints made of wire and composite: an investigation of lateral tooth mobility in vivo. Endod Dent Traumatol. 1995; 11:288-93.

31. American Academy of Pediatric Dentistry.Guideline on management of acute dental trauma.Pediatr Dent. 2008; 30:175-83.

32. Mandel U, Viidik A. Effect of splinting on the mechanical and histological properties of the healing periodontal ligament in the vervet monkey. Arch Oral Biol. 1989; 34:209-17.

33. Peterson LJ. Principles of oral and maxillofacial surgery. Vol 1. Philadelphia: W.B. Saunders, 1997. pp. 381-406.

34. Berger TD, Kenny DJ, Casas MJ, Barrett EJ, Lawrence HP. Effects of severe dentoalveolar trauma on the qualityof-life of children and parents. Dent Traumatol. 2009; 25:462-9.

35. Andreasen JO. Periodontal healing after replantation of traumatically avulsed human teeth.Assessment by mobility testing and radiography. Ada Odontol Scand. 1975; 35:325-35.

36. Cehreli ZC, Lakshmipathy M, Yazici R. Effect of different splint removal techniques on the surface roughness of human enamel: a three-dimensional optical profilometry analysis. Dent Traumatol. 2008; 24:177-82.

37. Bayar GR, Gulses A, Ozkan A, Sencimen M, Koc F. Management of a laterally luxated upper incisor caused by the hit of a rifle stock. Mil Med. 2011; 176: 468-71.

38. Burdon DW. Principles of antibiotic prophylaxis. World J Surg. 1998; 6:262.

39. Arthur G, Berardo N. A simplified technique for Maxillomandibular fixation. J Oral Maxillofacial Surg. 1989; 47:1234.

40. Feiglin B. Dental pulp response to traumatic injuries - a retrospective analysis with case reports. Endod Dent Traumatol. 1996; 12:1-8. 